\title{
Effect of stimulus onset delay in visual search by monkeys
}

\author{
JONATHAN VAUGHAN and ARTHUR A. STONE \\ Hamilton College, Clinton, New York 13323
}

\begin{abstract}
Control of visual fixations was studied as three stump-tailed macaques (Macaca arctoides) performed on a search task. The presentation of each visual stimulus was delayed for a short time (0-163 msec) after the beginning of a fixation on the location of that stimulus. The duration of visual fixations increased as a function of stimulus onset delay up to $130 \mathrm{msec}$. However, the increase in fixation duration was only half the stimulus onset delay imposed. This result suggests that oculomotor reactions are facilitated by longer foreperiods in a manner similar to other disjunctive reactions.
\end{abstract}

In reading, search, and similar tasks, humans make successive fixations at different locations in the visual field. The duration of these fixations, under normal circumstances, falls in a range between 160 and $500 \mathrm{msec}$, with the lower range predominating when simple stimuli and tasks are used (Arnold \& Tinker, 1939; LeGrand, 1967). Similarly, monkeys working on color and form discrimination have median fixation durations of 175 to 210 msec (Schrier \& Vaughan, 1973; Vaughan, Note 1).

The lower limit on the duration of human and monkey voluntary fixations is close to the reaction time of the saccadic system. Humans follow the step displacement of a target with a saccade about 200 msec later (Robinson, 1968); monkeys respond a little more slowly, about 240 msec behind the target (Fuchs, 1967b).

Saccadic reaction time imposes an upper limit on the rate at which fixations can occur in visual search no matter how little time might be required for the processing of visual information. One way of avoiding this limit is to present visual stimuli sequentially at a high rate in the same spatial location, so that the eyes need not be moved between presentations. Using such a paradigm, Potter and Levy (1969) found increasing accuracy of picture recognition as presentation time was increased from 125 to $2,000 \mathrm{msec}$ per picture; Kolers (1970) found that more than $250 \mathrm{msec}$ presentation time was required for correct report of the letters of an English word, and Pfafflin (1974) found an increase in accuracy

This research was supported by NIMH Grant MH 24855-01 to the first author, and NSF Grant GB 38580 to Allan M. Schrier. We thank Dr. Schrier for the hospitality of the Primate Behavior Laboratory at Brown University, where the experiments were conducted; Dr. Tom Brackett for the use of computing facilities at Colgate University; and Dr. George A. Gescheider, who sponsors this paper and accepts editorial responsibility for its contents. Requests for reprints should be addressed to Jonathan Vaughan, Psychology Department, Hamilton College, Clinton, New York, 13323. Arthur Stone is now at the State University of New York at Stony Brook. of report of words as interword time was increased from 100 to $250 \mathrm{msec}$. These studies suggest that perception and processing of visual information could not proceed much faster than the eyes can be moved, even when saccades are not necessary to obtain new visual information.

The experiment presented here was designed to dissociate the temporal requirements of visual information processing from the limits imposed by oculomotor reaction time, in a situation where normal eye movements were still permitted to occur. While monkeys worked on well-learned discrimination problems, presentation of the visual stimulus was delayed after the beginning of each fixation. In control blocks of trials, the two stimuli were displayed throughout each trial. In experimental blocks, a stimulus onset delay (SOD) was imposed between the beginning of each fixation on the location of a stimulus and the actual onset of that stimulus. The duration of each fixation on the discriminative stimuli was measured as SOD was varied over a 0 - to 163 -msec range.

The SOD effectively removes visual information during the first part of each visual fixation, as well as eliminating peripheral cues. The processing of a visual stimulus cannot begin until the delay has elapsed, so the duration of the fixation after stimulus onset is not constrained by the maximum rate at which saccades may occur. The effect of SOD on fixation duration depends on the times required by information processing and by the oculomotor system. First, if visual information were not processed in the early part of a fixation (because of postsaccadic suppression, for example), or if the minimum duration of a fixation in this task were determined solely by the time the eye was at rest, we would expect the manipulation of SOD to have no effect on the duration of a subject's fixations or on discriminative performance. Conversely, if the minimum fixation duration were determined by processing time, we would expect that SOD would increase fixation duration in proportion to the delay imposed. 


\section{METHOD}

\section{Subjects}

Three male stump-tailed monkeys (Macaca arctoides) served as subjects. The weights of these animals ranged from 12 to $15 \mathrm{lbs}$ and they were judged to be about 5 years old. The first subject, Alden, had previously served in experiments concerned with the transfer from repeated-reversal to learning-set formation in an automated apparatus and in pilot work during the development of apparatus for the present experiment. The second subject, Coy, had served in a study of eye-movement recording during learning-set formation; and the third subject, Grady, had previously served as subject in an experiment concerned with eye movements during ambiguous-cue-problem learning. The subjects were provided with about two-thirds of their normal daily ration in the form of $190-\mathrm{mg}$ banana-flavored whole-diet pellets and the remainder as commercial monkey chow.

\section{Apparatus}

Fixations were recorded using a computer-controlled corneal reflection method (Schrier, Povar, \& Vaughan, 1970; Vaughan, 1975). The subject's head was fixed using a skull-attached bracket that was clamped to the restraining chair (Freindlich, 1973). Stimuli subtending about $1 \mathrm{deg}$ were presented on an oscilloscope screen behind three 2-cm-diam transparent keys, placed in a triangular pattern (apex down), on a vertical panel $30 \mathrm{~cm}$ in front of the monkey's chest. The keys were separated by $15 \mathrm{deg}$ of visual angle.

\section{Procedure}

Each trial consisted of two phases. During the first, "calibration," phase the spatial adjustment of the apparatus was verified, using the lower center key. A fixation point was presented by dimly illuminating a single dot on the center key, while a warning tone $(400 \mathrm{~Hz}, 75 \mathrm{~dB}$ re 0.0002 microbars) was sounded. When the monkey had been fixating on this dot for at least $500 \mathrm{msec}$ (defined as no eye movement greater than $3 \mathrm{deg}$ in any $1 / 60$-sec interval), the dot was more brightly illuminated for $320 \mathrm{msec}$. The subject could then press the center key to initiate the discrimination phase of the trial. The long fixation that resulted from this procedure served to verify the spatial calibration of the equipment, as well as to insure that each trial started with a fixation on the same central location.

When the subject had successfully stared at and detected the increment in brightness of the fixation point, the second, "discrimination," phase of a trial began. The tone was terminated, and the two discriminative stimuli (patterns of seven or eight dots) were presented on the upper side keys as dictated by the experimental procedure; the subject's choice response ended the trial.

Part A. In control blocks of trials, the presentation of the discriminative stimuli began as soon as the subject pressed the center key (Figure 1a). In experimental blocks of trials, the onset of each discriminative stimulus was delayed for between 30 and $163 \mathrm{msec}$ (in steps of $1 / 60 \mathrm{sec}$ ) after the start of each fixation on one of the discriminative keys (defined as a fixation in either upper quadrant of the recording grid). Thus, each stimulus was visible only after the subject had been fixating on a key for up to $163 \mathrm{msec}$. Due to limitations inherent in the recording method (Vaughan, 1975), the shortest usable delay was $30 \mathrm{msec}$. If the fixation was directed at the same stimulus for at least the required delay, the stimulus was illuminated for the remainder of that fixation (that is, for as long as the animal's fixation continued to be recorded in the appropriate quadrant of the recording grid). When the monkey fixated on the left key, only the left stimulus was illuminated, and vice versa (Figure $1 \mathrm{~b}$ ). (The control conditions permitted peripheral vision of one stimulus while the animal fixated on the other.)

At the beginning of each session, the subject was placed in the chair, with its head restrained, and allowed to work on a simple brightness problem while the equipment was adjusted for
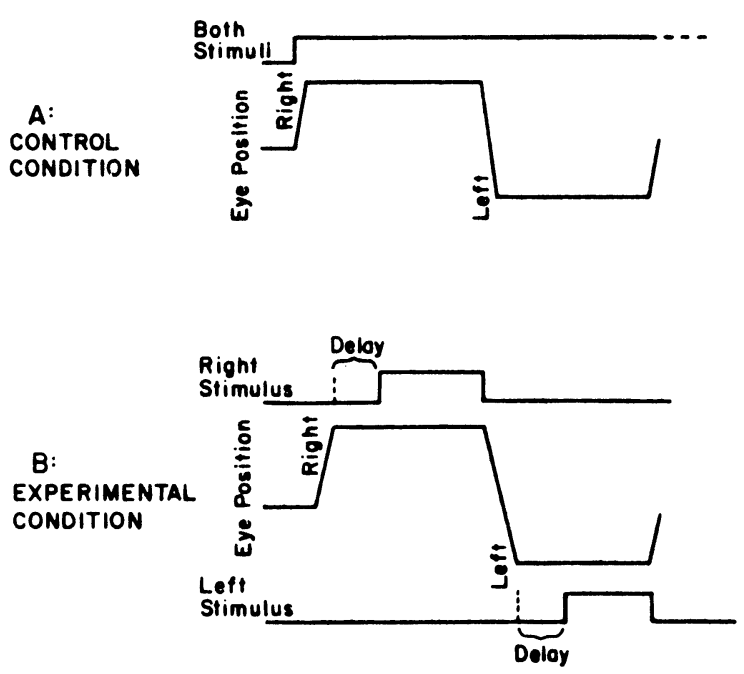

Figure 1. Procedures used in Parts A and B for the presentation of the discriminative stimuli contingent on eye orientation.

adequate recording of eye orientation, which routinely required no more than 30 or 40 trials. Data from these trials were not retained. Daily sessions were run until a total of about 400 trials had been completed, or until the animal's restlessness threatened to interfere with reliable data recording. Blocks of 20 control trials (in which both discriminative stimuli were illuminated as soon as the subject pressed the center key, regardless of the subject's eye movements) were alternated with 30-trial experimental blocks in which the onset of the stimuli was delayed after each visual fixation on the discriminative stimuli. The delays in each experimental biock were presented in a counterbalanced manner. Each experimental delay was run an approximately equal number of times in each session. The first subject performed on three problems; the second, on two; and the third, on one. The number of trials on each problem, and stimuli used, are shown in Figure 2. Experimentation was begun when performance on each problem was at least $90 \%$ correct.

Part B. While subjects continued to perform on the last problem of Part A, 20-trial control blocks (in which, as before, both discriminative stimuli were illuminated, regardless of the subject's eye movements) were alternated with 30-trial experimental blocks in which the SOD on one side, the variable SOD side, was varied between 30 and $163 \mathrm{msec}$ and the SOD on the other side, the constant SOD side, was always $30 \mathrm{msec}$. The variable SOD side was left or right in an equal number of sessions.

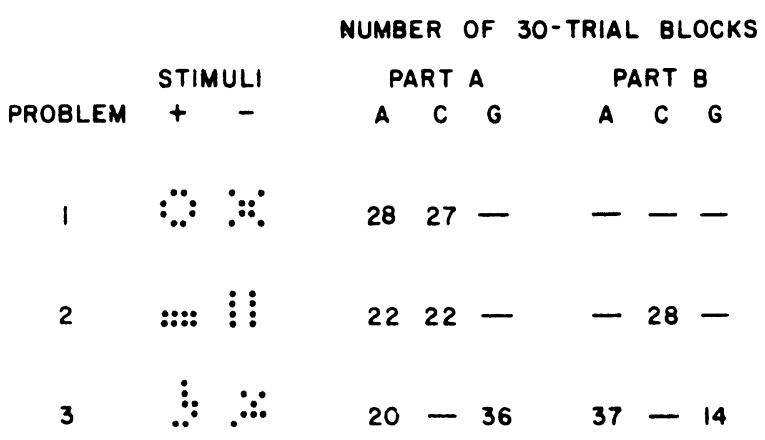

Figure 2. The stimuli used, and the number of experimental blocks of trials, for each problem. Subjects: $A=$ Alden, $C=$ Coy, $\mathrm{G}=$ Grady. 


\section{RESULTS}

The effect of SOD up to $130 \mathrm{msec}$ was consistent: Each additional $1 / 60$-sec (about $17 \mathrm{msec}$ ) delay added approximately $8.5 \mathrm{msec}$ to the total duration of each fixation on the discriminative stimuli. Fixation duration as a function of SOD in Part A is shown in Figure 3a. Choice-response accuracy and the number of fixations on the stimuli in each trial were not affected by SOD; responding was consistently $90 \%-100 \%$ correct, and about 1.3 scans of the stimuli occurred on each trial (a scan being defined as a shift in the fixation from one discriminative stimulus to the other).

In Part B, the duration of fixations on the variable SOD side increased as a function of delay, with SODs up to $130 \mathrm{msec}$ resulting in fixation duration increases of half the delay, as in Part A (Figure 3b). The duration of fixations on the constant SOD side had (except for one deviant point) a value about the same as the other 30 -msec delay points of both parts.

\section{DISCUSSION}

In both parts of the experiment, the duration of visual fixations was consistently related to the delay of onset of the discriminative stimuli, up to a delay of $130 \mathrm{msec}$. The data are well described by the function:

$$
\begin{aligned}
\text { Fixation Duration }=\text { Control Duration }(\text { about } \\
\\
200 \mathrm{msec})+ \text { Delay } / 2,
\end{aligned}
$$

except for the longest delays (greater than $130 \mathrm{msec}$ ). These results suggest that the duration of each fixation is largely controlled by the time of onset of the stimulus, but that postonset fixation duration may be shorter at the longer SODs without impairing performance accuracy. The results of Part B show that the fixation duration increase is specific to the stimulus delayed, and is not affected by the delay of the other stimulus.

The most interesting aspect of the present data is the observation of fixation duration increases that are less (by 50\%) than the SOD imposed. In effect, there is a "savings" (of half the SOD) in the time from the onset of the stimulus to the initiation of the next saccade. This could occur for a number of reasons.

Processing within a fixation might be more efficient if stimuli were presented after a delay. The detectability of near-threshold stimuli is reduced if they are presented during or within $75 \mathrm{msec}$ after the occurrence of a saccade (e.g., Volkmann, Schick, \& Riggs, 1968). The uniformity of slope in the present data through and beyond the expected range of such saccadic suppression effects suggests that this is not a factor in the present situation.

Reaction time to a stimulus might be a factor in the delay condition. Since the stimulus appears (and the next saccade is initiated) after a longer interval of rest following the previous saccade under SOD conditions, the saccadic reaction time might be shorter. Finger-movement reaction time to visual stimuli is shorter with longer foreperiods (Bertelson, 1967; Drazin, 1961; Lansing, Schwartz, \& Lindsley, 1959; Posner \& Boies, 1971; Woodworth \& Schlosberg, 1954), in humans, oculomotor reaction time is also shorter: Saslow's (1967) subjects tracked a visual stimulus where there was a gap of up to $250 \mathrm{msec}$ between the offset of a stationary fixation point and the onset of a lateral
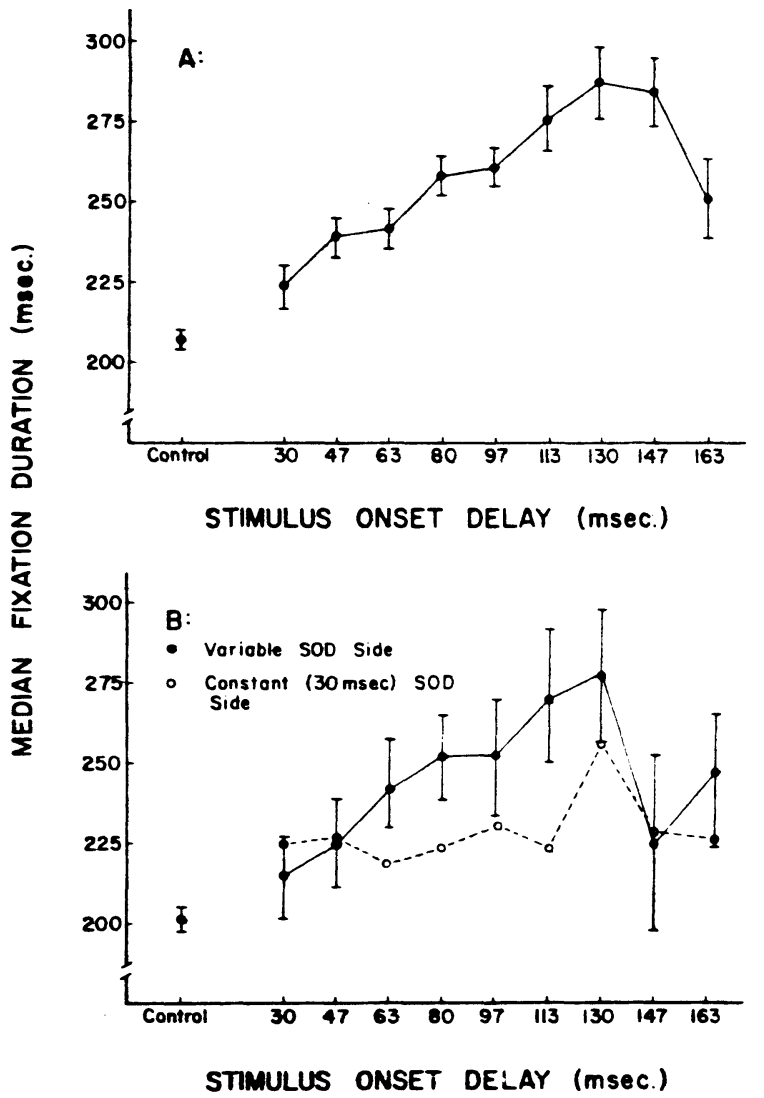

Figure 3. Median fixation duration for fixations of the discriminative stimuli for control and experimental conditions of Parts $A$ and $B$. Vertical bars indicate the $95 \%$ confidence limits of experimental points, estimated from the semi-interquartile range. In Part $A, N$ is 508 to 831 fixations per point, except control: $N=4,756$; in Part $B, N$ is 138 to 185, except control: $N=2,223$

target. With the simultaneous offset of the fixation stimulus and onset of the target, saccadic latency was about $200 \mathrm{msec}$; at a delay of $250 \mathrm{msec}$, latency was reduced to about $150 \mathrm{msec}$.

The breakdown in the linearity of the effect of SOD beyond $147 \mathrm{msec}$ may reflect a change in the subject's scanning strategy at SODs approaching the oculomotor reaction time (Fuchs, 1967a; Westheimer, 1954; Wheelis, Boynton, \& Cohen, 1966), perhaps involving a shift in control of fixation duration from stimulus onset to fixation duration itself. The increasing overlap of fixation duration for the variable and constant SOD stimuli at 130,147 , and $163 \mathrm{msec}$ in Part B also suggests such strategy changes. In any case, human subjects (whose strategies are more effectively controlled by instructions) have not shown this effect in similar experiments (Vaughan, Note 2).

In the present experiment, the delay of onset of a visual stimulus after the beginning of a fixation on that stimulus affects the duration of the fixation in a manner qualitatively similar to that of presenting a warning signal in disjunctive reaction time experiments. The subject-initiated saccadic movement prior to the fixation is analogous to the warning signal which the experimenter presents, and the SOD is analogous to the interval between the warning stimulus and stimulus presentation. Further research will be required to elucidate which of the individual stages of information processing within a fixation is affected by SOD. 


\section{REFERENCE NOTES}

1. Vaughan, J. A study of eye movements during learning of color and form visual discrimination problems by a rhesus monkey. PhD dissertation. Brown University, 1970. Available from University Microfilms, Ann Arbor. Michigan (No. 71-13947).

2. Vaughan. J. Delay of stimulus presentation afier the saccade in visual search. To be read at Eastern Psychological Association meetings. April 1976.

\section{REFERENCES}

Arnold, D. C. \& Tinker, M. A. The fixational pause of the eyes. Journal of Experimental Psychology, 1939. 25. 271-280.

BERTELSON. P. The time course of preparation. Quarterly Journal of Experimental Psychology. 1967. 19. 272-279.

Drazin. D. H. Effects of foreperiod, foreperiod variability, and probability of stimulus occurrence on simple reaction time. Joumal of Experimental Psychology, 1961, 62, 43-50.

Freindlich. A. Primate head restrainer using a nonsurgical technique. Journal of Appliced Physiology. 1973, 35, 934-935.

Fuchs. A. Saccadic and smooth pursuit eye movements in the monkey. Journal of Physiology, 1967, 191. 609-631. (a)

Fuchs. A. Periodic eye tracking in the monkey. Journal of Physiology, 1967, 193.161-171. (b)

Kolers. P. A. Three stages of reading. In $\mathrm{H}$. Levin \& J. P. Williams (Eds.). Basic studies on reading. New York: Basic Books, 1970. Pp. 90-118.

Lansing, R. W.. Schwartz. E., \& Lindsley, D. B. Reaction time and EEG activities under alerted and nonalerted conditions. Joumal of Experimentl Psychology. 1959. 58. 1 -7.

LEGrand. Y. Form and space vision (M. Millodot and G. G. Heath, Trans.) Bloomington: Indiana University Press. 1967. Pp. 367.
Pfafflin, S. M. The total time hypothesis. recall strategies. and memory for rapidly presented word strings. Memon and Cognition, 1974. 2. 236-240.

PosNer, M. I., \& Boies. S. J. Components of attention. Psichological Review, 1971, 78. 391-4()8.

Potter, M. C., \& LevY. E. I. Recognition memory for a rapid sequence of pictures. Journal of Experimental Psychology. 1969. 81. 10-15.

Robinson, D. A. Eve movement control in primates. Science. 1968. 161. 1219.1224.

SAsiow. M. G. Effects of components of displacement-step stimuli upon latency for saccadic eve movement. Jourmal of the Oprical Society of America. 1967, 57. 1024-29.

Schrier, A. M., Povar, M. L., \& Vaughan, J. Measurement of eye orientation of monkeys during visual discrimination. Behavior Research Methods \& Instrumentation, 1970. 2. 55-62.

Schrier. A. M. \& Vaughan, J. Eye movements during learning of color and form discrimination problems involving reversal and nonreversal shifts. Primates, 1973, 14. 161-178.

VAUGHAN, J. On-line. real-time recording of eve orientation using the corneal retlection method. Behavior Research Methods \& Instrumentation. 1975. 7. 211-214.

Volkmann, F. C., Schick. A. M. L., \& Riggs, L. A. Time course of visual inhibition during voluntary saccades. Journal of the Optical Society of America, 1968, 58, 562-569.

WestheIMER. G. Eve movement responses to a horizontally moving visual stimulus. A.M.A. Archives of Opthalmology. 1954. 52. 932-943.

Wheelis, L. L., JR., Boynton, R. M. \& Cohen, G. H. Eve-movement responses to step and pulse-step stimuli. Journal of the Optical Society of America, 1966. 56. 956-960.

WOODWORTH, R. S.. \& SCHLOSBERG, H. Experimental psychology: New York: Holt. 1954. Pp. 948.

(Received for publication, March 26, 1976.) 